\title{
Aspectos estruturais do sistema midiático brasileiro*1
}

Bruno H.B. Rebouças ${ }^{2}$

\section{Resumo}

Este artigo tem como objetivo sistematizar a formação dos meios de comunicação no Brasil, sua estrutura e a consequência de seu sistema, através de uma análise diacrônica, para entender a configuração infocomunicacional e sua concentração. Para tanto, pretendemos discutir o sistema midiático brasileiro e alguns dos aspectos legais cujas empresas informativas foram formadas, debatendo algumas questões inerentes à temática, especialmente sobre o papel desempenhado pelo Estado como regulador das concessões públicas, e se a adoção de um modelo privado de exploração da radiodifusão propiciou a propriedade cruzada e o oligopólio nos meios. Para essas e outras indagações, utilizamos as perspectivas histórica e estrutural, elaboramos um levantamento bibliográfico sobre a temática e suas ramificações, com dados pesquisados nos sistemas oficiais - lista de concessionários de rádio e TV do Ministério das Comunicações e do sistema acionário da Anatel. Ademais, discutimos as leis que regulamentam o setor infocomunicacional, especialmente o Código Brasileiro de Telecomunicações (CBT) e a Lei Geral de Telecomunicações (LGT), analisando as distorções dessas e também de outras leis e decretos. Finalizamos com uma análise sobre o problema da concentração midiática e suas diferentes formas, e o debate sobre a regulação dos meios.

Palavras-Chave: Radiodifusão; sistema midiático; regulação; Brasil; concentração.

\section{Structural aspects of the brazilian media system}

\begin{abstract}
This article aims to systematize the formation of the media in Brazil, its structure and the consequence of its system, through a diachronic analysis to understand the infocommunicational configuration and its concentration. Therefore, we intend to discuss the Brazilian media system and some of the legal aspects whose informative companies were formed, debating some issues inherent to the issue, especially about the role played by the State as regulator of public concessions, and whether the adoption of a private model of exploitation broadcasting provided cross-ownership and oligopoly. For these and other inquiries, we used the historical and structural perspectives, elaborating a bibliographic survey about the subject and its ramifications, with data searched in the official systems - list of radio and TV concessionaires of the Ministry of Communications and the Anatel shareholder system. In addition, we discuss the laws that regulate the infocommunication sector, especially the Brazilian Telecommunications Code (CBT) and the General Telecommunications Law (LGT), analyzing the distortions of these and also other laws and decrees. We conclude with an analysis on the problem of media concentration and its different forms, and the debate on media regulation.
\end{abstract}

Key words: Broadcasting; media system; regulation; Brazil; concentration.

\footnotetext{
*Revisor: Pedro Henrique Tenório

${ }^{1}$ Pesquisa realizada com bolsa da Capes, Ministério da Educação, processo no 0475-14-9.

2 Doutor em Jornalismo pela Universidad Complutense de Madrid, sem filiação.
} 


\section{Introdução: o modelo de exploração das concessões públicas}

A radiodifusão no Brasil começou a ser desenvolvida no mesmo período que no restante do mundo, seguindo o modelo privado de concessões de frequências de rádio e, posteriormente, de televisão, a grupos comerciais que, além de demonstrar condições financeiras e técnicas para desenvolver a tecnologia, também deveriam ajudar a incrementar a exploração comercial do novo meio de comunicação (HAUSSEN, 2001). O decreto 20.047 de 1931, de acordo com Haussen (2001, p. 32) estabelece que o serviço de radiodifusão seja de interesse nacional com fins educativos. "O Governo promoveria a unificação do serviço em uma rede nacional e definiria as concessões de emissoras, renováveis a cada dez anos, a organismos sociais ou privados”.

Pode-se dizer que o ocidente se dividiu em duas vertentes de exploração das concessões públicas, especialmente com a chegada da televisão nos anos de 1950. Os dois modelos de gestão foram o norte-americano, baseado em outorgas concedidas a grupos empresariais, sendo papel do governo garantir e gerar a concorrência entre os grupos; e o modelo mais comum e defendido na Europa, cujo estado se reservava o monopólio da utilização dos novos meios (CALIFANO; ROSSI; MASTRINI, 2013).

O modelo desenvolvido pelo Brasil foi o norte-americano em quase sua totalidade, mas sem levar em consideração os critérios sociais e educacionais, e sem introduzir mecanismos que impedissem a formação de possíveis oligopólios no setor da comunicação social (MOREIRA, 2000). No modelo dos Estados Unidos prevaleceu a exploração privada das concessões, porém, este se fundamentou no estímulo da competitividade, como demonstra o fato de haver sido capaz de impulsionar a formação de três grandes cadeias - CBS, NBC e ABC - que disputaram o mercado radiofônico em todo o país.

A radiodifusão nos EUA está controlada através de uma instituição pública, já que a Federal Communications Commission (FCC) está conectada ao Congresso Nacional, com independência funcional (LOPES, 2000). No Brasil, o controle só gerou uma concentração por parte dos grandes grupos de comunicação que mantiveram seu poder de informar ou gerou outros grandes grupos (SIMÕES; MATTOS, 2005) hegemônicos privados que estavam de acordo ou entrelaçados com o poder oficial, 
como foi o caso do Diários Associados e, posteriormente, da Rede Globo. Assim, ao adotar o sistema liberal de concessões, o Estado criou uma peculiar situação nessa vertente de exploração, pois não criou diversidade, mas sim concentração.

\begin{abstract}
O sistema de comunicações brasileiro foi constituído tomando por base o tradicional modelo liberal das sociedades capitalistas do Ocidente, com os Estados Unidos como referência principal [...]. No entanto, ao contrário da diversidade de conteúdo e da pluralidade de veículos implícitas na doutrina liberal, o Brasil tem uma situação peculiar. Uma única rede - a Rede Globo detém o "virtual monopólio" da televisão, consolidado e expandido durante o regime autoritário (LIMA, 2012, p. 148).
\end{abstract}

Diferentemente do que ocorreu nos Estados Unidos, onde foram aprovadas regras quase ao mesmo tempo do início da exploração do espectro, em 1934, no Brasil uma lei similar não apareceria até 1962, quando foi aprovado o Código Brasileiro de Telecomunicações (CBT), de número 4.117, que tem vigência até hoje, salvo em alguns artigos que foram atualizados pela Lei Geral de Telecomunicações (LGT), de número 9.472, que abordaremos mais adiante. Como o poder de conceder concessões era exclusivo do presidente da República até 1988, o Governo Federal não demonstrou preocupação com a formação de oligopólios na radiodifusão, especialmente com o caso dos Diários Associados de Assis Chateaubriand, que já havia consolidado sua hegemonia quando foi promulgado o CBT.

De acordo com Simões e Mattos (2005, p. 40), sobre esse modelo que foi forjada a televisão brasileira: “de inspiração marcadamente liberal, mas sem os organismos reguladores preocupados por um grande nível de concentração, que propiciasse seu fomento e defendesse sua pluralidade”. Estes autores complementam que a única preocupação que o Governo teve ao criar tais leis foi o de manter o controle dos novos meios de comunicação e os grupos centralizados no poder.

O rádio e a televisão, quando surgiram entre os anos de 1910 e 1940, foram
regulamentadas ou como serviço público estrito, sobre monopólio estatal,
caso dos países europeus ocidentais, ou como serviço de interesse público,
sobre exploração privada, caso dos Estados Unidos. Ou seja, nem a mais
radical das economias capitalistas se atreveu a estabelecer para a radiodifusão
um regime de exploração comercial eminentemente privado. E isso se deu na
forma de leis e regulamentos específicos, dos quais a norma mais eminente é
o Communications Act de 1934 (RAMOS, 2005, p. 66).

No Brasil, Simões e Mattos (2005) afirmam que apesar de alguns artigos do CBT atestarem um caráter estatal, como o artigo $7^{\circ}$, capítulo I, título IV: “compete 
privativamente à União a exploração diretamente ou mediante concessão [...] do serviço de radiodifusão sonora (regional ou nacional) e de televisão", o Código Brasileiro de Telecomunicações impulsionou um modelo privado de exploração sem preocupar-se da possível formação de monopólios e oligopólios em oposição a livre concorrência no setor. Para os autores, o CBT teve um foco muito mais centrado em regulamentar as questões políticas vinculadas às atividades audiovisuais do que regular os aspectos econômicos do setor.

\section{Apontamentos metodológicos para a análise}

Para a realização desta pesquisa, utilizamos uma série de métodos devido à complexidade do objeto de estudo. Como se trata de análise de emissores e meios de comunicação, pois buscamos analisar, ademais, sua formação e suas estruturas organizacionais, partimos de uma análise de tipo descritiva-explicativa, porque pretendemos como objetivo central "descrever o comportamento de uma ou mais variáveis dependentes em uma população"; e explicar, não somente observar variáveis, "mas estudar as relações de influência entre elas para conhecer sua estrutura e os fatores que intervêm nos fenômenos e sua dinâmica" (DEL RÍO, 2011, p. 86).

Para definir a estrutura dos grupos midiáticos, utilizamos especialmente os sistemas oficiais do Governo Federal, começando pela lista dos concessionários de radiodifusão do Ministério das Comunicações (MiniCom), criando um banco de dados com as informações das empresas e dos concessionários. O seguinte passo foi em direção ao Sistema de Acompanhamento de Controle Societário (SIAACO) da Anatel, que é acessado com os dados jurídicos da empresa. A construção desses dados foi o trabalho mais árduo e lento, pois apesar de haver os sistemas oficiais, estes ainda carecem de informação que ou estão incompletas ou inexistem. Assim, buscamos cruzar estas informações obtidas nesses sistemas e em pesquisas anteriores, com ferramentas de monitoramento da propriedade dos meios, bem como em informações corporativas das empresas e grupos, complementando os dados com informações, informes e notícias.

\section{Aspectos legais e ordenamento jurídico dos meios de comunicação}


O Código Brasileiro de Telecomunicações (CBT) foi criado para regulamentar todos os tipos de comunicação eletrônica, mas, após sua promulgação, apresentou falhas conceituais e brechas legais que denotam uma importante ambiguidade na interpretação de seus artigos, além de se inibir com a questão da definição de princípios que deveriam guiar "o uso privado de recurso natural de domínio público", de acordo com Herz (1987, p. 132). O Código não conseguiu, ou não quis abordar, a contradição profunda entre as possibilidades sociais das tecnologias da radiodifusão e de seu uso privado implantado no Brasil (HERZ, 1987). Outra crítica exposta por alguns autores se refere à indefinição em relação aos critérios que deviam orientar a concessão de licenças para sua utilização. Assim, afirma Simões e Mattos:

O que se vê é que uma atividade notavelmente pública, como a televisão,
trata de ter uma base em um modelo principalmente liberal, executada pela
iniciativa privada e com uma necessidade clara de regulação, em um país
com tradição "estatizante", onde o modelo regulador quase desaparece pela
dupla personalidade do Estado de proprietário-regulador (SIMÕES;
MATTOS, 2005, p. 38-39).

Neste sentido houve uma profunda indefinição do Estado em seu papel, pois, como regulador, ele falhou na distribuição das concessões não gerando diversidade, mas sim concentração, e no seu papel de proprietário, pois somente em 2008 houve a tentativa sistemática, por parte do Estado, de ser um proprietário-programador, com a fundação da Empresa Brasil de Comunicação. Além do mais, segundo Herz (1987, p. 133), o CBT somente estabeleceu uma definição clara: a da competência para atribuir as concessões, que até 1988 era exclusividade do presidente da República. Após a aprovação da Constituição, essa competência passou a ser do Congresso Nacional até 1997, quando foi promulgada a Lei Geral de Telecomunicações (LBT) e as concessões de serviços públicos passaram ao ser através de processo licitatório.

Em 1997, a LGT, número 9.472, extraiu a telefonia do âmbito de competência do "Código". Assim, o Brasil dividiu telecomunicações e radiodifusão, demonstrando mais uma vez a falta de preocupação pela formação de monopólios nas telecomunicações e na radiodifusão, na qual a propriedade cruzada é permitida dentro de um modelo desenvolvido para favorecer os grandes grupos de mídia, sem regulação econômica, em um modelo de autorregulamentação que não gerou disputa e equilíbrio, mas sim concentração econômica e geográfica. Tal determinação pode ser verificada no artigo 211 do LGT: “a concessão de serviços de radiodifusão sonora e de sons e 
imagens fica excluída da jurisdição da Agência, permanecendo no âmbito de competência do Poder Executivo", ressaltando que a Agência (Anatel) é uma autarquia vinculada ao Ministério das Comunicações, sendo órgão regulador das telecomunicações.

Após a privatização da Telebrás em 1998, a empresa foi dividida em 12 de acordo com a região de atuação. Uma das vencedoras do leilão foi a empresa espanhola Telefônica, que, desde a compra da empresa Vivo em 2010, e, posteriormente, com a compra da operadora de canais de TV a cabo GVT em 2014 - operação aprovada pela Anatel -, entrou no mercado de canais de TV por assinatura, concentrando grande porção desse mercado. Depois da compra das duas companhias, a Telefônica, que já liderava o mercado de telefonia celular com presença em 3,2 mil das mais de 5 mil cidades do país, passou a ter 105 milhões de clientes (Rosa, O Globo, 29 de julho de 2016), concentrando o setor. Além de sua grande escala de atuação nas telecomunicações, a Telefônica ostenta mais de 13\% do Grupo Prisa, dona do El País (El País, editoria Madrid, 22 de fevereiro de 2016). "Inclusive a lei brasileira de TV a Cabo, de 1995, sendo considerada uma das mais modernas e completas do mundo, não apresenta mecanismos que sejam capazes de inibir os apetites de concentração, frequentes no ambiente brasileiro" (SIMÕES; MATTOS, 2005, p. 40).

Além das duas leis mencionadas e da proibição constitucional expressada no artigo 220, parágrafo $5^{\circ}$ : “os meios de comunicação social não podem, direta ou indiretamente, ser objeto de monopólio ou oligopólio", a concentração de meios de comunicação foi inevitável dentro de um sistema de política de radiodifusão que privilegiou determinados grupos comerciais na exploração das concessões. À política de distribuição de concessões se soma a falta de um órgão regulador e a quase nula aplicação de critérios sociais e econômicos que favoreçam a competição entre os grupos, dificultando o surgimento de médias ou pequenas empresas informativas, ao contrário do que ocorre em outros países.

Os problemas da radiodifusão [...] são consequências da política adotada pelos governos militares e mantida sem reparos pela Nova República (1985-). Esta política de radiodifusão reduz o serviço público a uma atividade meramente privada-comercial. Mas, é uma política incoerente que nem esse caráter privado-comercial é adequadamente administrado: não há avaliação de mercado para viabilizar as emissoras, as concessões são superpostas indiscriminadamente em escala geográfica das emissoras [...]. De todo modo, 
se impõe a radiodifusão um caráter privado-comercial, mas não há sequer uma lógica comercial orientando esse modelo (HERZ, 1987, p. 44).

Neste sentindo, desde a formação dos meios predominam dois tipos de emissoras de rádio e televisão, oriundas deste modelo privado-comercial de exploração: "as controladas por grandes redes de rádio e televisão, e as obtidas por apadrinhados do poder" (HERZ, 1987, p. 44). A configuração atual dos meios de comunicação nos estados passa pela distribuição das permissões dadas em troca de apoio político às emendas constitucionais defendidas pelo ex-presidente José Sarney durante seu mandato e antes da promulgação da Constituição. Sarney e seu ministro de Comunicações, Antonio Carlos Magalhães, distribuíram 168 concessões de radiodifusão a 91 parlamentares, de acordo com dados levantados por Motter (1994). Estas 168 outorgas foram divididas em 79 rádios FM, 59 AM e 30 geradoras de televisão. As concessões acabaram por servir apenas para unificar o poder econômico e político que dominavam os estados da federação dentro da modalidade de "coronelismo eletrônico", levando em consideração a predominância de notórias famílias políticas que, além de controlar o cenário eleitoral, começaram a controlar também os meios de comunicação.

Essa configuração foi mais proeminente no Nordeste, região que apresenta o maior número de políticos proprietários de empresas infocomunicacionais (REBOUÇAS, 2018). São os casos das famílias Magalhães na Bahia, Maia e Alves no Rio Grande do Norte, Jereissati e Queiroz no Ceará, Mello, Tenório e Calheiros em Alagoas, Sarney e Lobão no Maranhão, Cavalcanti na Paraíba, Oliveira em Pernambuco, Franco em Sergipe e Lobo no Piauí. Estas e outras famílias criaram seus sistemas midiáticos com as concessões outorgadas pelo governo Sarney, que não teve nenhum interesse em sua distribuição senão o político.

Ademais da falta de interesse ou de preocupação por parte do governo, que devia exercer seu papel de regulador dos serviços públicos ante a formação de possíveis monopólios, para Simões e Mattos (2005, p. 39), no Brasil faz falta uma "cultura da concorrência", com o trato dos serviços públicos e outros tipos de regulação de atividades econômicas. "No Brasil se tendeu não somente a desconsiderar as preocupações sobre a competitividade, mas também a proteger os participantes contra eventuais possibilidades de concorrência". 
As leis que regulamentam a radiodifusão e as telecomunicações não se preocuparam com a possibilidade da formação de oligopólios nas duas áreas. O Código em nenhum dos seus artigos trata da propriedade cruzada, que é característica em formação de conglomerados midiáticos que reúnem diversas plataformas e meios em um mesmo âmbito de cobertura (LIMA, 2008), seja local, regional ou nacional. Diferente de outros países, como Estados Unidos, França e Reino Unido, no Brasil não há uma regulação econômica nem uma proibição clara contra a propriedade cruzada.

De acordo com Lima e Rabelo (2015), nesse ponto, o Brasil não seguiu o modelo dos Estados Unidos - "trusteeship model" - que apresenta, além de uma agência reguladora autônoma (Federal Communications Commision - FCC), regras e normas que limitam a propriedade cruzada em todos os níveis de atuação mercadológica dos grupos, que vigoram desde 1943, com modificações e adaptações atuais.

\footnotetext{
Quando criadas, estas normas impediam: 1- que um concessionário controlasse mais de uma emissora do mesmo tipo no mesmo mercado ("Duopoly Rule"); 2- que um mesmo concessionário controlasse mais de uma emissora de TV em VHF ou uma combinação de emissoras de rádio $\mathrm{AM} / \mathrm{FM}$ ("One-to-a-Market-Rule"); 3- que se outorgassem concessões de radiodifusão a pessoa física ou jurídica que exercesse o controle ou operasse jornal diário na mesma área geográfica ("Cross-Ownership Rule"); e, 4- que um mesmo grupo controlasse emissoras de rádio e televisão acima de certos limites percentuais de alcance dos domicílios no mercado nacional de televisão ("Multiple Ownership Rules") [LIMA; RABELO, 2015].
}

No Brasil, somente há duas tentativas de frear esse fenômeno: a primeira, através da lei de número 10.610 de 2002 , em seu artigo 38, letra G: "a mesma pessoa não poderá participar da administração ou da gerência de mais de uma concessionária, permissionária ou autorizada do mesmo tipo de serviço, na mesma localidade". Com este artigo poderíamos dizer que a propriedade cruzada estaria controlada (REBOUÇAS; DIAS, 2016).

Não obstante, o texto apresenta a característica de "brecha legal", como o de outras normas, pois não expressa proibição da propriedade, e tampouco define com claridade o que é administração e gerência. No mesmo artigo 38, por exemplo, há outro caso que dá margem a ambiguidade interpretativa. Em parágrafo único se lê: "Não poderá exercer a função de diretor ou gerente de concessionária, permissionária ou autorizada de serviço de radiodifusão quem esteja no gozo de imunidade parlamentar ou de foro especial". Ou seja, a lei proíbe que um político com mandato exerça a função de 
administrador de uma TV ou rádio, mas não o proíbe de ser proprietário e/ou sócio da empresa.

A segunda lei que tenta normalizar a questão da propriedade cruzada, mas, neste caso, faz referência a radiodifusão e telecomunicações é a lei de Serviços de Acesso Condicionado (SeAC), de número 12.485/2011, que proíbe que grupos de telecomunicações sejam proprietários de empresas de radiodifusão e vice-versa, proibindo expressamente que as empresas telefônicas distribuidoras de TV a Cabo, por exemplo, produzam conteúdo paras estes canais (INTERVOZES, 2015).

O grande problema para que exista um controle da propriedade cruzada e para regular economicamente os meios de comunicação com o objetivo de gerar uma maior pluralidade e diversidade de discursos, opiniões e linhas editoriais, e, portanto, mais competitividade entre as empresas, está no fato de que as informações sobre os proprietários, sócios e acionistas dos meios não sejam suficientemente transparentes. Como expomos mais acima, apesar de isso estar disponível através de fontes oficiais, como o Ministério das Comunicações e a Anatel, nos registros figuram somente os agentes donos de meios de forma individual, sem que seja possível estabelecer as conexões entre esses "proprietários individuais", que são beneficiários das concessões, e os proprietários de outras licenças que formam parte do mesmo conglomerado empresarial. Não se pode identificar, a partir destes registros, todas as conexões políticas presentes na propriedade dos meios.

Portanto, sob este sistema se formou os principais grupos de comunicação, alinhados em muitos casos com o poder político de forma direta, formando complexos conglomerados de alcance estatal e nacional (MARINONI, 2015, p. 5-6). Também se produziu a formação das redes entre os grupos nacionais e estaduais, na qual sempre resultam fortalecidos os meios de comunicação "cabeças de rede" que, entre outras coisas, impõem suas programações a suas afiliadas, concentrando não somente uma quantidade considerável de meios, mas também gerando uma concentração geográfica de conteúdo difundido e produzido quase em sua totalidade no Sudeste.

Segundo Marinoni (2015), o artigo 12 do decreto-lei 236/1967, em seu parágrafo $7^{\circ}$, deveria ser suficiente para impedir a perda de autonomia das afiliadas às grandes 
redes, que criam somente entre 10 a $15 \%$ de conteúdo próprio, muitas vezes resumido a programas informativos. Para tentar burlar este limite de cinco emissoras geradoras em todo o país, as emissoras que contam com concessões de alcance local para o estado designado se filiam a redes nacionais, podendo retransmitir o conteúdo das "cabeças de rede", que corresponde a $90 \%$ da programação dessas emissoras. Assim, por meio dessas redes, os grandes conglomerados nacionais ampliam seu poder de alcance em todo o território nacional, "ganhando o investimento publicitário" e sufocando a diversidade de produção de conteúdo no Brasil (INTERVOZES, 2015).

Este tipo de associação é proibida pelo mesmo decreto-lei e parágrafo $7^{\circ}$, onde se pode ler que as empresas concessionárias ou permissionárias do serviço de radiodifusão "não poderão estar subordinadas a outras entidades constituídas com a finalidade de estabelecer direção ou orientação única, através de cadeias ou associações de qualquer espécie". Sem embargo, a Anatel, responsável por regular tais associações, no informe "Mapeamento - TV Aberta" (2010, p. 23), reconhece a importância das afiliadas geradoras - por mais que se limitem a ser retransmissoras -, para que os grupos nacionais obtenham o êxito de audiência e de publicidade, justificando que estas redes não possuem figura jurídica definida. $\mathrm{O}$ informe afirma também que essa relação é fundamental, porque define o mercado nacional de radiodifusão. Mas nem o Ministério das Comunicações nem a Anatel possuem uma cartografia atualizada dessas redes.

Ademais da proibição constitucional, no artigo 220, acerca do oligopólio na comunicação, ainda de acordo com o decreto-lei 236/1967, que regulariza o limite de propriedade direta de concessões de televisão, em seu artigo 12, estabelece o limite em cinco concessões que cada grupo/pessoa pode chegar a acumular em âmbito local e nacional. Esta mesma regra inclui o rádio, mas permite um número alto de estações por entidades. A nível local, pode-se ter até quatro estações de ondas médias (OM) e seis de frequência moderada (FM). A nível estadual, um mesmo grupo pode ter três estações de OM e três de ondas tropicais (OT). Ou seja, somente com rádios, um mesmo grupo já pode formar um sistema concentrado de comunicação sonora.

Para finalizar estes aspectos legais, vale lembrar que a única área temática da Constituição Federal de 1988 que não teve um relatório final para a apreciação da Comissão de Sistematização (RAMOS, 2005), responsável de dar a redação final da 
Carta Magna, foi o da Comunicação Social. O motivo dessa ausência se encontra nas pressões que exerceram os empresários através da Associação Brasileira de Emissoras de Rádio e Televisão (Abert). Ao ser promulgada a Constituição, o capítulo da Comunicação referendava uma vez mais o caráter privado de radiodifusão nacional, apresentando "absurdos normativos", nas palavras de Ramos (2005), pois o Conselho de Comunicação Social, órgão regulador autônomo foi transformado em "um órgão decorativo auxiliar do Congresso Nacional” (RAMOS, 2005).

Além disso, a constitucionalização dos prazos de duração das concessões de rádio em 10 anos, e de televisão em 15 anos, consagrou o caráter privado da função pública, pois há em qualquer relação de concessão do estado, o processo de reversibilidade do serviço. "A concessão pública com um prazo de duração estipulado na Constituição, em vez de um contrato administrativo, e suscetível de cassação apenas por votação nominal no Congresso, converteu na prática as concessões em uma atividade essencialmente privada" (RAMOS, 2005, p. 69). Como os artigos constitucionais da Comunicação Social nunca foram regulamentados, pode-se dizer que, apesar de imoral, toda concentração midiática dos grupos empresariais e dos grupos políticos é legal, já que a falta de regulamentação dos artigos referentes à Comunicação implica que a norma constitucional não seja cumprida (LIMA; RABELO, 2015).

\section{A estrutura dos principais grupos de alcance nacional}

A estrutura dos meios audiovisuais brasileiros é caracterizada por um sistema com preponderância das emissoras privadas de rádio e televisão que se entrelaçam em torno da formação de redes (LIMA; RABELO, 2015), ou seja, um conjunto de emissoras que transmitem a mesma programação produzida por uma "geradora de televisão" com alcance nacional, chamada também de "cabeça de rede", de forma simultânea ou não. Além do mais, as concessões podem ser divididas em três componentes: a já citada "geradora de televisão" que desempenha, em suma, emissões de programação produzida em estúdios próprios; a "repetidora de televisão", modalidade de serviço destinado ao transporte de sinais de sons e imagens oriundos de uma estação geradora; a "retransmissora de televisão", que além de retransmitir de 
forma simultânea os sinais da estação "geradora", pode produzir $15 \%$ de conteúdo próprio $^{3}$.

Estamos em consonância com Lima e Rabelo (2015) que ao citarem o projeto os "Donos da Mídia", definem "redes de alcance nacional" as emissoras que alcançam mais de duas unidades da federação e "redes regionais" como emissoras que transmitem seus sinais de sons e imagens a até dois estados. Os autores ressaltam que "não são considerados 'redes de TV', os canais que operam exclusivamente nos serviços de TV por assinatura". Assim sendo, uma rede está formada por uma ou mais "geradoras" e um conjunto de emissoras "retransmissoras" próprias ou não. A Figura número 1 mostra a quantidade de emissoras por rede, ao nosso entender, considerando concessões "geradoras" tanto da cabeça de rede quanto das outorgas dos grupos afiliados. Porém, em "retransmissoras", considera-se as permissões próprias dos grupos de alcance nacional, sem considerar as outorgas dos grupos afiliados.

Figura 1 - Quantidade de emissoras por rede

\section{Número de emissoras comerciais por rede}

Commercial TV stations per network

\begin{tabular}{l|r|c}
\hline Emissora & Geradoras & Geradoras + Retransmissoras \\
\hline Rede Globo & 122 & 122 \\
\hline Sistema Brasileiro de Televisão (SBT) & 98 & 114 \\
\hline Rede Record de Televisão & 54 & 108 \\
\hline Rede Bandeirantes de Televisão & 24 & 101 \\
\hline RedeTV! & 5 & 155 \\
\hline Rede TV Cultura & 45 & 609 \\
\hline Central Nacional de Televisão (CNT) & 6 & 62 \\
\hline Rede Record News & 13 & 102 \\
\hline TV Gazeta S.Paulo & 1 & 90 \\
\hline Total & 368 & 1.463 \\
\hline
\end{tabular}

Fonte: Mídia Dados Brasil, 2018, p. 160.

Desta figura nos chama a atenção o número total de geradoras, 368, e a quantidade de estações pertencentes aos quatro maiores grupos televisivos que também são os líderes em audiência, como exposto na Figura 2, que juntas controlam 298 geradores de TV. Essa quantidade representa 80,98\% do total de emissoras geradoras.

3 Fontes: Anatel (disponível em: http://www.anatel.gov.br/setorregulado/servicos-de-radiodifusao); Decreto 5.371 de 2005, sobre o Regulamento dos Serviços de Retransmissão e Repetição (disponível em: http://www.planalto.gov.br/ccivil_03/_ato2004-2006/2005/decreto/d5371.htm). 
Levando em consideração a extensão do território nacional brasileiro, é possível identificar nove famílias que controlam os principais meios de comunicação do país, em termos de influência e na quantidade de veículos, tendo a maioria delas presença no setor audiovisual. Marinho (Organizações Globo); Macedo (Rede Record), Saad (Bandeirantes), Abravanel (SBT), Carvalho e Dallevo (RedeTV), Civita (Abril ${ }^{4}$ ), Mesquita (Estado) e Frias (Folha de S. Paulo). Não é possível esquecer o poder informativo-comunicacional do grupo RBS (Rede Brasil Sul), controlado pela família Sirotsky, especialmente na região Sul do país. O grupo RBS é proprietário do maior sistema de rádios do país, através da Rede Gaúcha SAT, com mais de 143 emissoras afiliadas em sete estados.

As Organizações Globo estão formadas, segundo os dados publicados em sua página institucional, pelas empresas Globo Filmes, responsáveis pela coprodução e produção de filmes. A Globosat é responsável pela programação dos canais de TV por assinatura, que inclui uma oferta de 30 canais diferentes. O grupo atua no mercado editorial e digital, com revistas e jornais, através da InfoGlobo e da Editora Globo. A InfoGlobo é responsável pela edição dos jornais O Globo, Extra e Expresso, além do jornal Valor Econômico, que a Globo adquiriu sua totalidade do Grupo Folha ${ }^{5}$. A Editora possui 14 revistas, além da edição de livros. Também faz parte do grupo a produtora musical e gravadora Som Livre. No rádio, atua por meio do Sistema Globo de Rádio, com estações próprias, como a CBN, com 34 estações, e a Rádio Globo, com 25, entre próprias e afiliadas. A Globo também atua com a plataforma ZAP, portal nacional de classificados on-line, e com o portal de notícias e conteúdo audiovisual Globo.com, relacionando na web as empresas do grupo.

Especificamente no campo da televisão aberta, segundo o relatório Mídia Dados Brasil (2018, p. 161), a Rede Globo conta com 122 estações que chegam a 5.490 municípios brasileiros, com um alcance de 99,51\% (202.716.683) da população brasileira que tem aparelho de televisão. Destas 122 estações, cinco são próprias e 118 pertencem a grupos afiliados. Além disso, a TV Globo tem, de acordo com nossa

\footnotetext{
${ }^{4}$ Em agosto de 2018 a editora Abril pediu Recuperação judicial e, embora esteja em processo de venda, consideramos importante para entender a magnitude que o grupo teve até metade de 2018, data do levantamento dos dados apresentados.

5 Disponível em: http://m.folha.uol.com.br/mercado/2016/09/1812854-grupo-globo-adquire-controle-dojornal-valor-economico.shtml.
} 
pesquisa no sistema da Anatel e do Ministério das Comunicações, 68 concessões de Retransmissoras de TV (RTV) além das inúmeras retransmissoras pertencentes aos grupos afiliados nos estados.

O Sistema Brasileiro de Televisão (SBT), de propriedade de Silvio Santos foi fundado em 1981, quando este recebeu a concessão que originou a TVS-Canal 11, com sede no Rio de Janeiro, após o fechamento da Tupi, a primeira TV do país, propriedade do Diários Associados de Chateaubriand (PIERANTI, 2006). O SBT foi beneficiado com a redistribuição das concessões dos "Associados", no governo do general Figueiredo, que tentava gerar mais competição no setor com a fundação de mais emissoras de televisão. Essa distribuição originou duas novas cadeias, sendo elas o SBT e a TV Manchete, hoje RedeTV (INTERVOZES, 2015). Atualmente, o grupo pertencente a Silvio Santos possui 114 estações de televisão, com oito próprias, embora o nome da família Abravanel apareça na lista de nove estações (MARINONI, 2015), atingindo mais de 190 milhões de pessoas. Ao contrário dos outros grupos, o SBT não aparece na lista de concessões de rádio nem detém jornais em sua propriedade.

Por sua vez, o registro da Rede Record, de propriedade do bispo e fundador da Igreja Evangélica Universal do Reino de Deus, Edir Macedo, tem em sua rede um total de 108 estações, com 12 próprias (MARIONI, 2015), considerando apenas o nome do bispo Macedo, de acordo dados apurados no sistema da Anatel e do Ministério das Comunicações, sem contar as concessões em nome de outros sócios e das retransmissoras dos grupos afiliados. Adquirida na década de 1990, a Record tornou-se a segunda emissora com a maior audiência do país. Devemos considerar também as emissoras pertencentes à Igreja Universal, através da Rede Aleluia de rádio, que está composta por mais de 64 estações próprias e afiliadas, presentes em $75 \%$ do território nacional, ou em 22 dos 26 estados e no Distrito Federal. "No entanto, a Rede Record de Televisão não se apresenta como vinculada a essa rede de rádio, talvez para manter sua estratégia de disputar o público laico" (MARINONI, 201, p. 10).

Fundada em 1967 por João Jorge Saad, a TV Bandeirantes controla 49 emissoras, sendo 14 próprias, alcançando $89 \%$ da população brasileira. O grupo Band conta, ademais, com 191 retransmissoras próprias e 234 RTV de grupos afiliados, de acordo com Marinoni (2015) e Santos (2004), dados que vão ao encontro e ampliam as 
informações da Figura número 1. Ademais das emissoras de televisão, este grupo tem o segundo maior número de emissoras de rádio do país, de acordo com a pesquisa Mídia Dados Brasil (MDB) 2018, com um total de 62 emissoras entre FM e AM. O grupo de Saad também possui dois canais de TV a cabo: Band Sports e Band News. Band News também conta com 10 estações de rádio sob o mesmo nome. Finalizando a estrutura das principais emissoras de televisão do país, encontra-se a RedeTV que engloba um total de 40 emissoras de televisão, sendo 5 próprias e 155 entre "geradoras" e "retransmissoras".

Se observarmos os dados de audiência, a ordem das quatro emissoras muda em consideração ao número de propriedades. Juntas correspondem a 69,73\% da audiência do país, segundo o relatório Mídia Dados Brasil 2018, pesquisa produzida pelo Grupo Mídia de São Paulo. Deste total, a Globo acumula 37,36\% da audiência, enquanto Record tem $14,56 \%$, SBT tem $14,01 \%$, e Band conta com 3,8\%. Se acrescentarmos a quinta rede de televisão aberta, a RedeTV, com sua audiência média de 1,04\% anual, as redes comerciais chegam a $70,77 \%$ da audiência, em uma clara concentração de mercado e de conteúdo, além de um oligopólio geográfico, já que todas as cabeças de rede estão no Rio de Janeiro e em São Paulo.

\section{Figura 2 - Audiência das emissoras de TV}

Audiência TV Aberta 2017

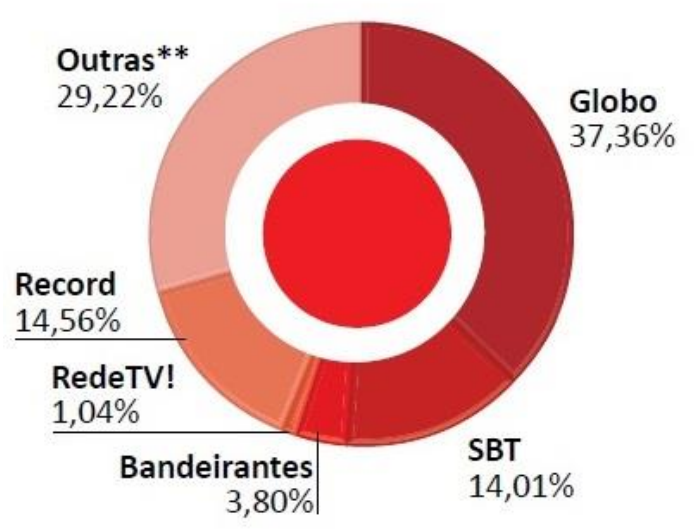

**Outras: Record News, RPTV (TV Brasil), TV Câmara, TV Justiça, TV Senado, OCA, Canais Pagos e Não Identificado/Cadastrado. Target Universo Regiöes Metropolitanas 2017: 68.821.100

Fonte: Mídia Dados Brasil (2018, p. 161). Figura editada para facilitar a leitura.

Com alcance em sete estados do país, concentrados nos três da região Sul, o grupo RBS é também uma potência na propriedade cruzada, que converge diferentes 
plataformas e meios de todos os tipos. O grupo conta com 147 emissoras de rádio, entre próprias e afiliadas. Além de quatro jornais, entre eles o Zero Hora que é o mais lido do Rio Grande do Sul. Possui também a emissora RBS TV e suas 12 emissoras próprias divididas por todo o estado. A RBS TV é afiliada da Rede Globo desde 1967. O grupo de propriedade da família Sirotsky também tem uma editora de livros, uma distribuidora de publicações, um portal de notícias que alcança o estado vizinho, Santa Catarina, onde também é líder de audiência, além de uma gráfica que imprime outros jornais e trabalhos impressos.

Por fim, a respeito da estrutura dos meios de comunicação, a criação da Empresa Brasil de Comunicação (EBC) em 2007, através da lei 11.652, foi uma iniciativa para unir todos os meios de comunicação públicos que existiam no país sob uma só estrutura e organização, materializando a criação de um perfil efetivamente público dessas empresas. Apesar de representar uma medida relevante na tentativa de equilibrar a área com uma maior presença do setor público, ainda está muito longe da influência e do alcance das emissoras comerciais. Um dado que demonstra essa infrarrepresentação dos meios públicos no Brasil é o que aponta a Pesquisa Brasileira de Mídia (2015, p. 133): apenas $31 \%$ da população conhece a existência da TV Brasil, principal meio da EBC.

A Empresa Brasil de Comunicação (EBC) conta com 50 emissoras, sendo quatro próprias, e está formada por duas redes de televisão: a TV Brasil e a TV Brasil Internacional; e por uma agência de notícias: Agência Brasil. Assim como pela Rádio Agência Nacional e do sistema público de Rádio, composto por oito emissores: Nacional FM Brasília, Nacional Rio AM, Nacional Alto Solimões, Nacional Brasília AM, Nacional Amazônia, MEC FM Rio, MEC AM Rio. De acordo com a página institucional $^{6}$, a EBC se distingue como um sistema público de meios de comunicação, caracterizado "por sua independência editorial [...]. A rede de emissoras produz conteúdos diferenciados que a singulariza por espelhar de maneira mais fidedigna a complexidade cultural brasileira, ocupando um espaço complementar, não preenchido pelos canais privados". Além dos meios de comunicação explorados pela EBC, em nível Federal, há os veículos explorados pela Câmara, Senado, Supremo Tribunal e Exército. O poder executivo ainda explora outro canal, a TV NBR, voltada para notícias

\footnotetext{
${ }^{6}$ Disponível em: http://www.ebc.com.br/institucional/arquivo/sobre-a-ebc.
} 
sobre as ações do Poder Executivo e a cobertura de eventos dos Ministérios e da presidência da República. Estes canais têm caráter estatal e/ou governamental, e são diferentes dos canais explorados pela EBC, que são meios públicos.

\section{Os sistemas de rádio e o mercado editorial}

No mercado radiofônico, ainda que haja uma forte concentração e conexões de grupos e redes que caracterizam a propriedade cruzada, há mais concorrência que na área televisiva. As principais emissoras de rádio são formadas pela já mencionada Rede Gaúcha SAT (com 143 emissoras), seguida da Bandeirantes AM/FM (62), Band FM (45) e BandNews (10), totalizando 117 emissoras - ainda que apareçam separadas na pesquisa do Grupo Mídia, pertencem ao mesmo grupo empresarial. Em terceiro aparece a Jovem Pan FM (56) e JP AM (35), que juntas somam 91 emissoras em todo o país. A Rede Transamérica também apresenta duas empresas separadas, Hits (48) e Pop (12), que formam um grupo com 60 emissoras de rádio. O Sistema Globo de Rádio soma 60 emissoras através da CBN e da Globo AM. O sistema Estadão, propriedade do Grupo Estado de São Paulo, conta com 10 emissoras radiofônicas.

No mercado editorial - revistas e jornais -, os grandes grupos estão localizados em São Paulo e Rio de Janeiro, concentrando um grande número de publicações, que se mesclam com diversas plataformas e diferentes meios, formando oligopólios cada vez maiores, seguindo uma tendência mundial, na qual "as maiores empresas midiáticas têm agora mais propriedades que nunca e também mais conteúdo próprio, que se emite através das distintas plataformas" (CASTELLS, 2009, p. 116) que impactam sobre o mercado tanto através da concentração empresarial e econômica, quanto em termos de centralização geográfica da produção de conteúdos e informações (BECERRA; MASTRINI, 2009).

Nesse aspecto, a concentração geográfica de conteúdo é mais latente no mercado editorial. Esta forte centralização dos meios impressos que se produz no Brasil, em torno a grandes metrópoles, é um padrão na maioria dos países da América Latina. "Este impacto também debilita o espaço público e empobrece a disposição de diferentes versões sobre o real por parte das audiências/leitores, condenando a uma sub- 
representação a vastos setores que habitam o "interior" dos países" (BECERRA; MASTRINI, 2009, p. 35). No Brasil, os grandes grupos editoriais, assim como as televisões “cabeças de rede” e os sistemas de rádio, estão especialmente no Sudeste.

O maior grupo editorial que existiu no Brasil até agosto de 2018 foi o Grupo Abril, com 25 publicações, destacando a revista Veja que alcançava mais de 1 milhão de leitores. No seu auge, o grupo Abril chegou a ter a concessão de uma televisão, a MTV, vendida ao grupo Spring, que edita a revista Rolling Stone (INTERVOZES, 2015), mas a transação segue suspensa pelo Ministério das Comunicações. Apesar da concorrência na área editorial entre os grupos, Abril ostentava o controle dentro de uma estrutura monolítica, com a maior indústria gráfica da América Latina e uma distribuidora de publicações diversas, Dinap, que alcançava todo o país.

Em número de publicações de revistas, o segundo maior grupo é o Alto Astral, com 18 títulos diferentes, ainda que entre eles não figure nenhuma revista jornalística influente. Outros dois grupos editorais (ambos com 18 publicações), são Escala e Todateen, sendo esta responsável pela publicação da segunda revista mais vendida do país, a Caras. A editora Globo conta 12 títulos, destacando a revista Época. Com 11 títulos aparece a Editora 3, tendo a revista IstoÉ como destaque ( GRUPO DE MÍDIA SÃO PAULO, 2016).

O setor de jornais, ainda que os diários líderes tenham circulação em todo o país, concentram $95 \%$ das suas vendas em seus estados e regiões vizinhas ${ }^{7}$, de acordo com Instituto Verificador de Comunicação (IVC). Os cinco jornais mais lidos do país são: Folha de S. Paulo, O Globo (RJ), Super Notícia (Belo Horizonte), O Estado de S. Paulo e Zero Hora (Porto Alegre). Entretanto, se levamos em consideração o alcance nacional destes jornais, este número se reduz a três periódicos: Folha, O Estado e O Globo.

O Grupo Estado edita o jornal mais antigo do estado de São Paulo, fundado em 1875. Além do diário, o grupo conta com 10 rádios sob a marca Eldorado FM e Rádio Estadão. Contudo, com dados do Media Ownership Monitor Brasil (MOM-Brasil, 2017), as rádios Estadão 700 AM e 92,9 FM, estão em contrato de arrendamento ${ }^{8}$ a dois

\footnotetext{
${ }^{7} \mathrm{O}$ relatório completo pode ser acessado aqui: http://ivcbrasil.org.br/blog/post.asp?id=128.

8 Disponível em: https://brazil.mom-rsf.org/br/proprietarios/empresas/detail/company/company/show/ grupo-oesp-estado/.
} 
grupos religiosos: Rede Nossa Rádio, da igreja Internacional da Graça de Deus, e para igreja Comunidade Cristã Paz e Vida, respectivamente. Além disso, o grupo Estado é concessionário da TV Eldorado, arrendada ao grupo Top Sports, antigo proprietário dos canais Esporte Interativo. Segundo relatório do MOM-Brasil, ao anunciar o fim da gestão direta das rádios e televisão, o Estado afirmou que com o arrendamento das rádios ia centralizar seus investimentos em plataformas digitais. O Estadão conta ainda com uma agência de notícias, a OESP Mídia e o portal de notícias on-line que unifica todas as plataformas do grupo.

O jornal líder de audiência nacional, Folha de S. Paulo, pertence à família Frias. O grupo também é proprietário do jornal Agora São Paulo, e editou o jornal diário especializado em economia, Valor, até 2016, quando vendeu suas ações ao grupo Globo. A Folha também conta com Alô Negócios, um periódico de classificados que circula em dois estados do Sul; uma editora de livros, Publifolha, um instituto de pesquisa, Datafolha, cinco revistas e/ou suplementos com circulação nos jornais do grupo, além de quatro outras empresas, entre gráficas e distribuidoras. O Grupo Folha também é dono do portal UOL, que é, de acordo com dados institucionais ${ }^{9}$, a maior empresa brasileira de conteúdo, produtos e serviços de internet.

\section{A ramificação infocomunicacional}

Moraes (2013, p. 19) descreve a configuração da estrutura dos grupos de comunicação através da metáfora de uma árvore, na qual em seus galhos se refugiam os setores de informação e entretenimento, meios de comunicação em geral, que se unem com os outros galhos através de outros negócios na mesma área - cinema, fonografia, livros, internet, entre outros. Tudo isso formando um "fio condutor invisível", nas palavras do autor, que são as tecnologias avançadas que se entrelaçam e formam um conjunto unificado em uma mesma linha editorial, de interesses político-empresariais e objetivos comerciais. Dessa forma, todas as empresas dos grupos formam um circuito comum de "elaboração, irradiação e comercialização de conteúdo, produtos e serviços".

O sistema dos meios do Brasil pertence, em sua grande totalidade, a um reduzido número de corporações, nove com escala nacional, que são responsáveis por produzir

\footnotetext{
${ }^{9}$ Disponível em: http://www1.folha.uol.com.br/institucional/conheca_o_uol.shtml.
} 
um volume alto de dados, sons e imagens e que, devido à concentração geográfica já demonstrada, detêm a visão cultural do eixo Sul/Sudeste, não representando os valores locais e a diversidade cultural do vasto território nacional em toda sua complexidade e diferenças.

Para que existisse um equilíbrio maior que assegurasse o direito de acesso de todos os públicos aos grandes meios de comunicação, Serrano (2013, p. 77) defende que é, ou deveria ser, papel do Estado garantir os valores de pluralidade, democracia e a participação social nos meios. O estado brasileiro deveria regulamentar os artigos da Constituição para que os grupos comerciais cumprissem as diretrizes que as leis sobre os meios de radiodifusão estabelecem. $\mathrm{O}$ setor da comunicação foi deixado quase por completo à iniciativa privada, com pouca capacidade de regulação, desequilíbrio e concentração.

Depois de expor a estrutura dos maiores grupos midiáticos do país, vimos que há muitos meios de comunicação no Brasil, mas esse número elevado não reflete necessariamente na pluralidade de informações, já que há uma concentração na produção dos conteúdos por poucos grupos e, além desse aparente pluralismo em termos numéricos, dentro desta estrutura de oligopólio há uma absoluta hegemonia da televisão sobre os outros meios de comunicação, como aponta o estudo brasileiro sobre meios de 2015, da Secretaria de Comunicação Social da Presidência da República (SECOM-PR), que afirma que $95 \%$ da população consome televisão e, dessa porcentagem, 73\% de maneira diária (SECOM, 2015). Portanto, a força e a capacidade de influência da televisão sobre a sociedade são altas. O que resulta muito característico e preocupante, no sistema brasileiro, é que o meio televisivo está direta ou indiretamente sob a propriedade de políticos profissionais, gerando a denominação de coronelismo eletrônico, especialmente nos meios de alcance local, com particular ascendência no Nordeste.

Outro ponto necessário para ser abordado neste tópico, é acerca de um aspecto que também afeta a concorrência entre os meios: o investimento da publicidade oficial nas empresas informativas, especialmente em momentos de crise política. Em 2016, após a destituição de Dilma Rousseff (PT), o ex-presidente Michel Temer (MDB) fez uma redistribuição dos investimentos institucionais aos grandes grupos. De acordo com 
Sergio Lirio (Carta Capital, 28 de outubro de 2016) ${ }^{10}$, em comparação a 2015, entre os meses de maio e agosto de 2016, o Governo Federal incrementou a publicidade da TV Globo em 24,4\%, do grupo Abril - através da revista Veja - em 624\%; da Folha e do portal UOL, em 78,1\%; e da TV Band, na alta cifra de 1.129,4\% em relação ao governo anterior.

\begin{tabular}{|c|c|c|c|c|c|}
\hline \multicolumn{6}{|c|}{ Propaganda estatal federal - emissoras de TV } \\
\hline \multicolumn{6}{|c|}{ (valores em $R \$$ ) } \\
\hline \multirow[b]{2}{*}{ Emissora } & \multicolumn{3}{|c|}{2012} & \multicolumn{2}{|c|}{2000 a 2012} \\
\hline & Valor em $2012\left(^{*}\right)$ & $\begin{array}{l}\% \text { sobre } \\
\text { total gasto } \\
\text { com TVs } \\
\text { em } 2012\end{array}$ & $\begin{array}{l}\text { Audiência da } \\
\text { emissora em } \\
2012\left({ }^{* *}\right)\end{array}$ & $\begin{array}{c}\text { Valor total } \\
\text { acumulado de } \\
2000 \text { a } 2012\left(^{*}\right)\end{array}$ & $\begin{array}{l}\text { \% sobre o total } \\
\text { recebido desde } \\
\text { o ano } 2000\end{array}$ \\
\hline Globo & $495.270 .915,28$ & $43,98 \%$ & $43,70 \%$ & $5.863 .488 .865,02$ & $54,7 \%$ \\
\hline Record & $174.382 .548,15$ & $15,49 \%$ & $14,30 \%$ & $1.571 .067 .107,79$ & $14,7 \%$ \\
\hline SBT & $153.552 .688,48$ & $13,64 \%$ & $12,20 \%$ & $1.643 .631 .418,59$ & $15,3 \%$ \\
\hline Band & $100.549 .938,34$ & $8,93 \%$ & $5,40 \%$ & $913.779 .773,38$ & $8,5 \%$ \\
\hline Rede TV! & $39.777 .101,16$ & $3,53 \%$ & $1,70 \%$ & $371.837 .027,61$ & $3,5 \%$ \\
\hline Demais emissoras & $49.563 .103,30$ & $4,40 \%$ & & $556.084 .890,32$ & $5,2 \%$ \\
\hline TV fechada & $112.953 .614,07$ & $10,03 \%$ & & $737.712 .200,05$ & $6,9 \%$ \\
\hline Total geral & $1.126 .049 .908,78$ & $100 \%$ & $100 \%$ & $10.716 .883 .603,20$ & $100,0 \%$ \\
\hline
\end{tabular}

(*) Dados fornecidos pelo Instituto para Acompanhamento da Publicidade (IAP), usados pela Secom para monitorar esses gastos. Os valores estão ndexados pelo IGPM-FGV.

$\left.{ }^{* *}\right)$ Ibope PNT - Média anual - Target: ABCDE 18+, Ambos os sexos, faixa horária: $6 \mathrm{~h}$ às $24 \mathrm{~h}$

Fonte: Secom (Secretaria de Comunicação Social da Presidência da República)

Neste ponto, retroagindo alguns anos, se analisarmos os dados oficiais divulgados pela Secom em 2012, último levantamento dessa magnitude ao qual tivemos acesso, referentemente a publicidade oficial no meio televisivo de 2000 a 2012, os gastos do Governo Federal e de suas empresas com publicidade também geraram concentração no mercado, com uma das concorrentes absolvendo mais de $50 \%$ das receitas.

FIGURA 3 - Gasto estatal com propaganda de 2000 a 2012

Nota-se que mesmo dentro de um mercado concentrado em termos de audiência, a diferença na arrecadação da publicidade oficial atinge níveis díspares entre as emissoras, de maneira que gera mais concentração entre os oligopólios televisivos, com a TV Globo acumulando mais de $54 \%$ do total do investimento federal em propaganda em 12 anos. A justificativa está no fato de a Secom levar em consideração para

\footnotetext{
${ }^{10}$ Reportagem disponível em: http://www.cartacapital.com.br/revista/924/o-golpe-sera-televisionado.
} 
distribuição de recursos a audiência de cada rede, como exposto na Figura 3, em seu segundo asterisco. Com este critério, o faturamento com publicidade oficial causa uma ruptura entre as concorrentes e amplia a concentração econômica de poucas empresas, distanciando a primeira, Globo, das demais colocadas, que em termos de audiência (veja-se a figura 2), concentra mais que as outras quatro emissoras concorrentes juntas.

\section{Concentração multimídia e suas diferentes formas}

Como demonstram Becerra e Mastrini (2009), quando falamos de concentração de meios de comunicação temos que acrescentar ao processo a estrutura direta que as empresas têm, mas incluindo e superando seus contornos e diferentes atividades, pois a concentração não costuma ser só no campo informativo, mas também em diferentes áreas que se agregam dentro dos diferentes ramos de uma estrutura que engloba de tudo, incluindo as telecomunicações e o conjunto das indústrias culturais. Atualmente, com a convergência tecnológica, a concentração corporativa chegou a níveis que até agora eram impensáveis.

Tanto no Brasil como na América Latina, o fenômeno da concentração se configurou muito rapidamente devido a estrutura política-econômica-social. Quase todos os países passaram por governos autoritários e a partir deles se materializou o ecossistema midiático-comunicacional que existe no continente. Assim, os estudos com enfoque em sociopolítica da comunicação dividiram-se em duas linhas: a geográfica e a econômica (MASTRINI; BECERRA, 2006), ambas identificadas no Brasil. Em suma, a concentração geográfica centraliza seu foco na produção, distribuição e consumo. Ainda que no Brasil os níveis do alcance da televisão cheguem a mais de $90 \%$ em termos de distribuição, há uma clara concentração geográfica no Sudeste em termos de produção de conteúdos informativos e entretenimento, o que gera um efeito de homogeneização sobre a diversidade cultural do país.

Já a linha econômica está relacionada na complexa conexão entre o poder político, o econômico e os proprietários dos meios. Segundo podemos afirmar, no Brasil, a conivência entre poder político e econômico convergem com muita clareza, em termos de propriedade dos meios de comunicação, representando o que Hallin e Mancini (2008) conceituam como "paralelismo político". Vale lembrar que os autores 
dividem o sistema midiático em três. Nos interessa o "Modelo Mediterrâneo", cuja característica fundamental é a proximidade entre os sistemas midiático e político. Apesar de o Brasil não estar na análise desse modelo, podemos incluí-lo notadamente porque apresenta as mesmas características dos países analisados, com o agravante de ter políticos como proprietários de empresas informativas, gerando a "confluência político-midiática efetiva” (REBOUÇAS, 2018).

Com a configuração do mercado midiático-informacional brasileiro, podemos afirmar, ainda, que a diversidade real de meios é frágil devido à concentração na propriedade, audiência e faturação de alguns grupos. Se, no que se refere à estrutura e propriedade, a diversidade é frágil, em termos de conteúdo, essa pluralidade é ainda mais baixa, já que há uma homogeneização dos assuntos e da forma de abordá-los, com o triunfo do "padrão de qualidade" imposto a todos os membros de uma rede. Acreditamos que a existência de um grande número de meios de comunicação não necessariamente implique na configuração de um ecossistema midiático diverso que requer, além da quantidade de meios, diferentes formatos, abordagens, linguagens e que busque refletir a visão de grupos sociais, políticos e culturais sem acesso direto aos meios de comunicação e a produção de conteúdo.

Portanto, a concentração é um fenômeno que impacta não somente no mercado e na competição entre os postulantes, mas no fluxo de informações, com efeitos mais negativos à sociedade. Além do mais, a concentração é um processo que "restringe a ação profissional do jornalista e a circulação de ideias, e implica um problema políticosocial-cultural que deve encontrar no direito uma pronta solução" (LABATE et al., 2013, p. 161). Devemos entender que os meios de comunicação funcionam em uma lógica empresarial, mas não podemos esquecer que, ao deter o monopólio "virtual da construção, manutenção e reprodução de capital simbólico" (LIMA, 2012), a imprensamídia carrega uma função social que é uma prerrogativa pública de defesa da sociedade frente aos três poderes e que deve reproduzir a diversidade da sociedade onde está inserida.

Em um sistema midiático, há que considerar não somente o problema econômico que as concentrações geram, quando chegam a provocar uma posição hegemônica de algum dos agentes, impedindo o desenvolvimento de uma mínima concorrência por 
parte de outras empresas. Além destes efeitos nas dinâmicas econômicas, os processos de concentração podem ter consequências mais graves no terreno político, prejudicando o pluralismo informativo que é de vital importância no sistema democrático e na sua sobrevivência (LABATE et.al., 2013, p. 168).

Acreditamos que a concentração é um problema de regulação, regulamentação e de se encontrar, em cada sociedade, um modelo de lei que impeça os grandes oligopólios e gere mais diversidade e pluralidade informacional. Albornoz e Leiva (2017, posição 418-442) apontam que há quatro fatores que prejudicam a diversidade nos sistemas audiovisuais. Identificamos todos no caso brasileiro, mas daremos publicidade ao terceiro ponto por considerar neste contexto o mais fundamental: "ausência de normas claras para guiar os prestadores do serviço audiovisual", já que nunca houve uma regulamentação dos artigos referentes à Comunicação Social da Constituição. Neste caso, o problema não é a falta de uma estrutura pública para interpretar as leis existentes e não regulamentadas e criar uma regulação de mercado. $\mathrm{O}$ problema radica da capacidade de influência e pressão que o setor da comunicação exerce no poder que legisla, já que a criação de um conselho de comunicação e de um órgão regulador choca-se de forma frontal contra os interesses dessas grandes corporações, que terminam impondo-se aos interesses gerais e, inclusive, das normas vigentes.

\section{O projeto de regulação no Brasil e as regras em outros países}

A discussão sobre a regulação econômica dos meios e da regulamentação dos artigos da Constituição no Brasil sempre gera o debate entre censura versus democratização. Este tema gera uma grande controvérsia em sua interpretação por parte da população em geral e entre os profissionais da área que tendem a assumir o discurso negativo das empresas, até o ponto de ter preconcepções a respeito da regulação dos meios (REBOUÇAS, 2018). Não obstante, o projeto de regulação que tenta entrar em tramitação no Congresso, através de uma petição popular, procede de instituições defensoras da democratização dos meios não pertencentes a partidos políticos, contradizendo a intenção dos grandes grupos midiáticos de associar qualquer debate sobre regulação/regulamentação ao viés político e ao controle institucional-editorial. 
O projeto de regulação que existe atualmente é de iniciativa do Fórum Nacional pela Democratização da Comunicação (FNDC) e de outras 264 associações e instituições conectadas direta ou indiretamente com o tema. O projeto de Lei de Iniciativa Popular de Comunicação Social Eletrônica - Lei da Mídia Democrática elaborado na I Conferência Nacional de Comunicação (CONFECOM, 2009), está composta por 33 artigos. A Lei de mídia democrática ${ }^{11}$ apresenta em seu primeiro artigo o objetivo central de regulamentar os artigos da Constituição. Deve-se ressaltar o artigo 5, capítulo 2, acerca da divisão das concessões de radiodifusão e a criação de um sistema mais equitativo que diferencia as frequências entre públicas, privadas e estatais.

As concessões de carácter público estariam destinadas a associações e comunidades, ampliando o acesso da cidadania a uma estrutura midiática com programação regional e local. As Privadas estariam destinadas a empresas comerciais com fins lucrativos ou não. As Estatais, por sua vez, estariam destinadas a órgãos públicos para a transmissão de atos e ações dos poderes Executivo, Legislativo e Judiciário. O ponto central desse sistema de divisão está baseado no modelo de $33 \%$ do dial para cada grupo do sistema. Além do mais, no capítulo 6, consta um modelo de gestão econômica dos meios públicos, entre eles, a colaboração de 3\% sobre a margem de lucro na publicidade dos grupos privados.

Entretanto, a área da comunicação tem sido particularmente sensível às demandas de novas regras de operação. As empresas informativas, desde a divulgação de ideias, valores e abordagens subjetivos, argumentam que a intenção daqueles que defendem a criação de novos padrões é implantar a censura e a restrição a livre circulação de ideias e opiniões. Os adeptos das mudanças argumentam de outra forma. "Digamos que a indústria está monopolizada e que um novo marco legal estaria baseado na defesa de um pluralismo de opiniões” (MARINGONI; GLASS, 2012, p. 75).

É necessário mencionar que países tradicionalmente mais democráticos que o Brasil criaram organismos e regras específicas para conter a concentração desenfreada e a propriedade cruzada dos meios de comunicação, por exemplo, França, Reino Unido e Estados Unidos, sendo que estes contemplaram algumas exceções e mudanças com a flexibilidade do Regulamento em 2007, quando passou a ser permitido, de acordo com o

\footnotetext{
${ }^{11}$ O Projeto completo pode ser acessado aqui: http://www.paraexpressaraliberdade.org.br/projeto-de-lei/.
} 
desenvolvimento das tecnologias, que em algumas zonas e localidades específicas existisse a possibilidade de desenvolvimento de estruturas empresariais sob a propriedade cruzada. No projeto de Lei dos Meios do Brasil, também se inclui a possibilidade de estabelecer este tipo de limitações - da propriedade cruzada - a fim de evitar as distorções que se geram no mercado e que podem afetar a concorrência entre as empresas de comunicação.

Nessa exceção, em algumas localidades, são levadas em consideração a audiência da emissora de televisão e o número de meios independentes presentes na mesma localidade. No caso brasileiro, isso seria possível em localidades de $100 \mathrm{mil}$ ou menos habitantes. Nos Estados Unidos, que já se encontra em vigor, essa flexibilidade serve para as vinte maiores áreas do mercado, de um total de 210 , com a condição que a emissora de TV, por exemplo, não esteja entre as quatro mais assistidas e que haja outras oito emissoras independentes (BRANT, 2011).

No caso francês, há regras específicas para o mercado de alcance nacional e local acerca da propriedade cruzada. Por exemplo, nenhuma pessoa física ou jurídica pode ostentar ao mesmo tempo uma licença para televisão e rádio e ser proprietário de um jornal com circulação nacional se ambos são distribuídos na área de alcance do outro meio. No Reino Unido, não é permitido ser concessionário do Canal 3 (ITV) que, de acordo com Brant (2011), é a segunda maior emissora de TV e a primeira entre as redes privadas - se o grupo já conta com um ou mais jornais de circulação nacional que juntos alcancem $20 \%$ da parcela de mercado.

A limitação da propriedade cruzada e sua regulação econômica se justificam praticamente com os mesmos argumentos dos problemas de concentração em todos os mercados econômicos. Isso é, inclusive, necessário em termos puramente economicistas, considerando que, em todos os âmbitos, a concentração tende a prejudicar os consumidores, já que em um mercado caracterizado pelo oligopólio há controle de preços, provedores e canais de distribuição dos serviços, e isso gera efeitos que praticamente evitam a entrada de novos agentes no mercado. No caso dos meios, além de todos estes efeitos econômicos, se veem afetados a qualidade e o pluralismo informativo, assim como a diversidade de conteúdos, reduzindo-se a uma homogeneização o espaço plural e diverso característico da sociedade brasileira, por 
exemplo, o que ameaça "a liberdade de expressão e a liberdade de imprensa ao impedir o acesso das vozes da maioria da população brasileira ao espaço de debate público cuja mediação, apesar das TICs, (os grandes meios) monopolizam” (LIMA, 2013).

Para Lima (2013) há "controle" na mídia brasileira e isso é feito pelos oligopólios e não pelo Estado, que se omitiu do seu papel regulador desde a promulgação da Constituição.

São esses oligopólios que - contrariando as normas e princípios da Constituição em vigor - "controlam" a mídia [...]. Esse "controle" da mídia pelos oligopólios privados se sustenta de diferentes formas. Uma delas é o poderoso (e bem remunerado) lobby que nos últimos 25 anos (31 anos em 2019) tem pressionado continuamente deputados e senadores e impedido que normas e princípios da Constituição de 1988 relativas à comunicação social sejam regulamentados. Sem serem regulamentados, não são cumpridos (LIMA, 2013).

Portanto, no caso brasileiro é extremamente necessário que o debate sobre uma regulação deixe de ser enviesado pelo discurso dos grandes meios de comunicação cujo argumento central é a "tentativa de controle da mídia" e passe ao campo das ideias que visam estabelecer uma melhora na distribuição do ecossistema infocomunicacional buscando ampliar, com um modelo próprio de regulação, a diversidade e a pluralidade na propriedade dos meios, nas suas posições geográficas, possibilitando assim a entrada de novos agentes e o surgimento de meios independentes e locais que traduzam a complexidade social do Brasil. E antes de qualquer coisa, é necessário a regulamentação dos artigos da Constituição que tratam da Comunicação Social para estabelecer o que a lei considera monopólio e oligopólio, cuja carta magna proíbe em seu artigo 220.

\section{Considerações finais}

O papel do Estado no tema da radiodifusão é variado, pois, ademais de regular as frequências e distribuí-las com um critério técnico, há de se levar em consideração a regulação da concorrência entre as empresas de cada indústria, especialmente em termos de propriedade das diferentes plataformas que se concentram sob a propriedade cruzada. É papel de o Estado evitar a formação de oligopólios e a concentração de diferentes meios sob o mando de poucos proprietários, e incentivar, através de uma regulamentação, a variedade de conteúdos que deve haver em todas as sociedades (BUSTOS, 1993, p. 46). O Estado também atua como programador de conteúdo, através 
dos meios públicos e estatais. Como se viu nas epígrafes anteriores, neste sentido, o estado brasileiro falhou em ambos os aspectos: tanto em sua função de legisladorregulador, como na programação de conteúdos através dos meios públicos.

Ao organizar os meios públicos sob uma mesma empresa, a EBC, o Estado começou a tentar recuperar um espaço que havia perdido desde o início da radiodifusão. Ainda que com muito menor alcance em comparação aos sistemas comerciais, a EBC é um avanço importante na evolução do Estado como programador de conteúdo, como acontece em países desenvolvidos, especialmente na Europa. Contudo, é necessário que a Empresa Brasil não sofra um desmantelamento e que mantenha seu carácter público para tentar construir um legado como propulsor de opiniões e debates.

Ao não cumprir sua função entre os meios de comunicação de alcance nacional, com as emissoras cabeças de rede, o Estado tampouco se preocupou com a formação de oligopólios. Estamos de acordo com Pérez Gómez (2002, p. 41) quando afirma que "os poderes públicos estão obrigados a controlar as operações de concentração dos meios de comunicação e a proibir aquelas concentrações através das quais determinadas empresas possam chegar a acumular um poder excessivo em um determinado mercado". Como vimos nas figuras 2 e 3, pode-se dizer que o Brasil chegou a esse nível, pois a Globo tem anualmente uma audiência maior que as outras quatro grandes emissoras a nível nacional (Record, SBT, Band e RedeTV), além do faturamento em propaganda, que gera mais concentração. Esta estrutura, além de daninha à sociedade por claras razões, atinge o equilíbrio do mercado e limita a entrada de novos agentes econômicos na disputa, já que é um mercado regido por políticos legisladores que, em muitos casos, são também donos de meios e de suas estruturas conglomerares.

Por fim, acreditamos que o principal desafio dos governos é gerar as condições adequadas para a criação de políticas de comunicação que garantam o pluralismo informativo e a diversidade de conteúdo. Essas políticas deveriam regular determinadas dinâmicas do mercado que possam prejudicar esse pluralismo. A regulamentação teria que corrigir essas disfunções que o mercado brasileiro apresenta. Portanto, com este artigo buscamos contribuir com o debate e com a bibliografia existente, visando à ampliação da discussão através do conhecimento científico e da publicidade dos dados apresentados para conhecimento do público em geral. 


\section{Referências bibliográficas}

ALBORNOZ, Luis A.; LEIVA, $\mathbf{M}^{\mathbf{a}}$. Trinidad García. (Ed.) Diversidad e industria audiovisual: El desafío cultural del siglo XXI. Edição Kindle. Ciudad de México: Fondo de Cultura Económica, 2017.

ANCINE - Agência Nacional de Cinema: Ministério da Cultura. TV Aberta - mapeamento, 2010. Disponível em:

https://oca.ancine.gov.br/sites/default/files/televisao/pdf/mapeamento_tvaberta_2010.pdf.

Acesso: janeiro 2018.

BECERRA, Martín; MASTRINI, Guillermo. Los dueños de la palabra - acceso, estructura y concentración de los medios en la América Latina del siglo XXI. Buenos Aires, Argentina: Prometeo, 2009.

BRANT, João. Por que e como se limita a propriedade cruzada. 2001. Disponível em: http://www.direitoacomunicacao.org.br/content.php?option=com_content\&task=view\&id=7514 . Acesso: julho 2015.

BRASIL, ANATEL - Agência Nacional de Telecomunicações. Sistema de Acompanhamento de Controle Societário. Brasília, DF, 2019. Disponível em:

https://sistemas.anatel.gov.br/siacco. Acesso em: novembro de 2017.

BRASIL, Ministério da Ciência, Tecnologia, Inovações e Comunicações. Dados Abertos. Brasília, DF, 2019. Disponível em:

https://www.mctic.gov.br/mctic/opencms/indicadores/DadosAbertos.html. Acesso: maio 2019.

BRASIL. Secretaria de Comunicação Social da Presidência da República. Pesquisa Brasileira de Mídia - Hábitos de consumo de mídia pela população brasileira. Brasília, DF, 2015. Disponível em: http://www.secom.gov.br/atuacao/pesquisa/lista-de-pesquisas-quantitativas-equalitativas-decontratos-atuais/pesquisa-brasileira-de-midia-pbm-2015.pdf/view. Acesso: fevereiro 2019.

BUSTOS, Juan Carlos Miguel de. Los grupos multimedia: estructuras y estrategias en los medios europeos. Barcelona: Bosch, 1993.

CALIFANO, Bernadette; ROSSI, Diego; MASTRINI, Guillhermo. Introducción. In: MASTRINI, Guillermo; BIZBERGE, Ana; CHARRAS, Diego (Ed.). Las políticas de comunicación en el siglo XXI. Buenos Aires, Argentina: Crujia Ediciones, 2013.

CASTELls, Manuel. Comunicación y Poder. Madrid: Alianza Editorial, 2009.

DEL RÍO, Olga. El proceso de investigación: etapas y planificación de la investigación. In: VILCHES, Lorenzo (Org.). La investigación en comunicación - métodos y técnicas en la era digital. Barcelona: Gedisa editorial, 2011.

GÓMEZ, Alberto Pérez. El control de las concentraciones de medios de comunicación: derecho español y comparado. Madrid: Dykinson, 2002.

GRUPO DE MÍDIA SÃO PAUlO. Mídia Dados Brasil, 2016. Disponível em: https://dados.media/\#!/cover\#\%2Fmosaic. Acesso: março 2018.

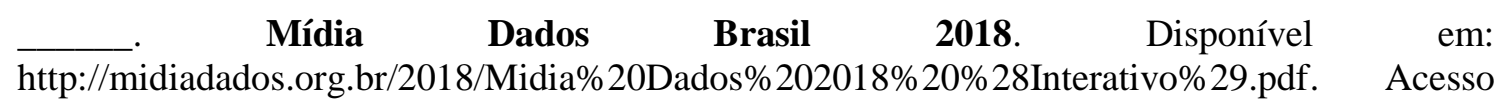
em março 2019.

HALLIN, Daniel; MANCINI, Paolo. Sistemas mediáticos comparados. Barcelona: Hacer editorial, 2008. 
HAUSSEN, Doris Fagundes. Rádio e Política - Tempos de Vargas e Perón. Porto Alegre, Brasil: Edipucrs, 2001.

HERZ, Daniel. A história secreta da Rede Globo - sim eu sou o poder. Porto Alegre: Tchê Editora, 1987. Disponível em: http://www.hlage.com.br/E-BooksLivrosPPS/A\%20Historia\%20Secreta\%20da\%20Rede\%20Globo.pdf. Acesso em: fevereiro 2017.

INTERVOZES . Caminhos para a luta pelo direito à comunicação no Brasil - como combater as ilegalidades no rádio e na TV. 2015. Recuperado de: http://intervozes.org.br/arquivos/interman004cldcnb.pdf. Acesso em: março 2018.

LABATE, Cecilia; LOZANO, Luis; MARINO, Santiago; MASTRINI, Guillermo; BECERRA, Martín. Abordajes sobre el concepto de concentración. In: MASTRINI, Guillermo; BIZBERGE, Ana; CHARRAS, Diego. (Ed.). Las políticas de comunicación en el siglo XXI. Buenos Aires, Argentina: Crujía Ediciones, 2013.

LIMA, Venício. As concessões de radiodifusão como moeda de barganha política. Revista Adusp, São Paulo, n. 42, p. 26-33, 2008. Disponível em: http://www.adusp.org.br/files/revistas/42/r42a02.pdf. Acesso em: 2016.

LIRIO, Sergio. O será televisionado. Carta Capital, São Paulo, edição 924, 28 out. 2016. Disponível em: http://www.cartacapital.com.br/revista/924/o-golpe-sera-televisionado. Acesso em: jul.2016.

de. Liberdade de Expressão X Liberdade da Imprensa: Direito à Comunicação e Democracia. 2. ed. São Paulo: Publisher Brasil, 2012.

. Mídia: Teoria e Política. 2. ed. São Paulo: Editora Fundação Perseu Abramo, 2012.

. Sim. Existe 'controle' da mídia no Brasil. Disponível em: http://observatoriodaimprensa.com.br/jornal-de-

debates/_ed761_sim_existe_controle_da_midia_no_brasil. Acesso em: abril-maio 2019.

; RABELO, Bráulio Santos. Monopólio ou oligopólio? Contribuição ao debate.

Disponível em: http://observatoriodaimprensa.com.br/interessepublico/_ed833_monopolio_ou_oligopolio_contribuicao_ao_debate. Acesso: abril-maio 2019.

LOPES, Vera. A lei da selva. In: BUCCI, Eugenio. (Ed.). A TV aos 50: criticando a televisão brasileira no seu cinqüentenário. São Paulo: Fundação Perseu Abramo, 2000.

MARINGONI, Gilberto; GLASS, Verena. A regulação da mídia na América Latina. Revista Desafios do Desenvolvimento, v. 9 , n. 71, p. 74-79. Disponível em: http://www.ipea.gov.br/desafios/images/stories/PDFs/desafios071_completa.pdf. Acesso em: janeiro 2015.

MARINONI, Bruno. Concentração dos meios de comunicação de massa e o desafio da democratização da mídia no Brasil. Análise 13, de 2015, Friedrich Eberte Stiftung Brasil. Disponível em: http://intervozes.org.br/wp-content/uploads/2016/02/Projeto-FESArtigoconcentracao-meio.pdf. Acesso em: janeiro 2018.

MASTRINI, Gillermo; BECERRA, Martín. (Dir.). Periodistas y magnates: primer informe sobre estructura y concentración de las culturas en América latina. Buenos Aires, Argentina: Prometeo Libros, Instituto Prensa y Sociedad, 2006.

MORAES, Denis. Sistema mediático y poder. In: MORAES, Denis; RAMONET, Ignacio; SERRANO, Pascual. Medios, poder y contrapoder: de la concentración monopólica a la democratización de la información. Buenos Aires, Argentina: Biblos, 2013.

MOREIRA, Sonia Virgínia. O rádio no Brasil. Rio de Janeiro, Brasil: Mil Palavras, 2000. 
MOTTER, Paulino. O uso das concessões das emissoras de rádio e de televisão no governo Sarney. Comunicação e Política, v. 1, n. 1, p. 89-116, 1994.

PIERANTI, Octavio Pena. Políticas para a mídia: dos militares ao governo Lula. Lua Nova, $\mathrm{n}$. 68, p. 91-121, 2006. Disponível em: http://dx.doi.org/10.1590/S0102-64452006000300004. Acesso em: setembro 2015.

RAMOS, Murilo. A força de um aparelho privado de hegemonia. In: BRITTOS, Valerio Cruz; BOLAÑO, Cesar. (Ed.). Rede Globo: 40 anos de poder e hegemonia. São Paulo, Brasil: Paulus, 2005.

REBOUÇAS, Bruno H.B., Dias, Elaine. N. Radio and the media regulation in Brazil. Radio, Sound and Society Journal, v. 1, n. 1, p. 42-56. Disponível em: http://ecrearadioresearch.eu/rssjournal/index.php/rssj/article/view/24/23. Acesso: outubro 2017.

REBOUÇAS, Bruno H.B. Los dueños de las empresas de comunicación y la utilización política de los medios en Brasil: el caso de los estados Bahía, Ceará y Río Grande del Norte. 2018. 475f. Tese (Doutorado em Jornalismo) - Facultad de Ciencias de la Información Universidad Complutense de Madrid, 2018.

ROSA, Bruno. Após nove meses, Vivo finaliza compra da GVT. O Globo, Rio de Janeiro, 29 mai. 2015. Disponível em: https://oglobo.globo.com/economia/apos-nove-meses-vivo-finalizacompra-da-gvt-16301635. Acesso em: jul. 2016.

SANTOS, Suzy dos. Uma convergência divergente: a centralidade da TV aberta no setor audiovisual brasileiro. 2018. Tese. Universidade Federal da Bahia, Salvador, 2004.

SERRANO, Pascual. Democracia y libertad de prensa. In: MORAES, Denis; RAMONET, Ignacio; SERRANO, Pascual. Medios, poder y contrapoder: de la concentración monopólica a la democratización de la información. Buenos Aires, Argentina: Biblos, 2013.

SIMÕES, César Ferreira; MATTOS, Fernando. Elementos histórico-regulatórios da televisão brasileira. In: BRITTOS, Valerio Cruz; BOLAÑO, Cesar (Ed.). Rede Globo: 40 anos de poder e hegemonia. São Paulo: Paulus, 2005. 